\title{
Induction of Gentamicin Resistance by Visible Light
}

\author{
MARY CATHERINE HARRIS, WILLIAM T. SPECK, JOSEPH M. CAMPOS, AND \\ RICHARD A. POLIN ${ }^{(17)}$ \\ The Children's Hospital of Philadelphia and the University of Pennsylvania School of Medicine, Philadelphia, \\ Pennsylvania and Rainbow Babies and Children's Hospital, Case Western Reserve University, Cleveland, Ohio
}

\begin{abstract}
Summary
Recent studies have demonstrated the ability of visible light or phototherapy to modify the intracellular DNA of prokaryotic and eukaryotic cells. The present study was undertaken to determine the effect of light used in phototherapy on antibiotic resistance in prokaryotic cells using tester strains of gentamicin-sensitive $E$ scherichia coli and Staphylococcus aureus. A growing population of the tester microorganisms was inoculated on plates containing nutrient medium and gentamicin. Experiments were performed to determine the effect of blue light on the induction of gentamicinresistant mutants. The plates were divided into two populations, one of which was illuminated, while the other was kept in the dark to serve as a control. During photoirradiation, the plates were protected from direct sunlight and air cooled to maintain a temperature of $27^{\circ} \mathrm{C}$. The sample distance from the light source was adjusted to maintain a fluence rate $(450 \mathrm{~nm})$ of $141 \mathrm{uW} / \mathrm{cm}^{2}$. Control experiments were performed to investigate the effect of photoirradiation on the media and gentamicin. An increased frequency of mutation to gentamicin resistance was seen in the irradiated population of bacteria. The mutagenic effect was observed over a wide range of gentamicin concentrations and correlated in a linear fashion with increasing duration of photoirradiation. There was an inverse correlation between the size of the bacterial inoculum and the recovery of mutant bacteria.
\end{abstract}

\section{Speculation}

In view of the demonstrated ability of high-intensity visible light to modify intracellular DNA and induce mutations in bacterial populations, the relationship between the widespread use of phototherapy and the emergence of multiple antibiotic-resistant bacteria in nursery populations needs to be determined.

Since the introduction of sulfonamides in the 1940's, antibiotic resistance has become an increasingly common problem in neonatal intensive care units. Selective pressure brought about by the widespread use of antimicrobial agents has produced flora with altered antibiotic sensitivity patterns. The decision to withhold antibiotics when they are marginally indicated is unacceptable to many because of the consequences of delaying therapy in the truly septic infant. A particularly serious problem has been the development of bacteria resistant to aminoglycoside antibiotics. The frequency of appearance of spontaneous kanamycin and gentamicin-resistant mutants is low and has been estimated at less than one in $10^{10}$ cells per generation (5). The mutation frequency might theoretically be increased by agents with the capacity to modify intracellular DNA. Speck and Rosenkranz (10-13) have demonstrated that high intensity illumination with blue light $(450 \mathrm{~nm})$ will produce genetic alterations both in eukaryotic and prokaryotic cells as well as in isolated DNA in the presence of bilirubin or riboflavin. Because of its widespread acceptance for treating neonatal hyperbilirubinemia, phototherapy has the potential for pro- ducing large numbers of resistant organisms. The purpose of the present study is to investigate the role of phototherapy in the induction of gentamicin resistant bacteria.

\section{MATERIALS AND METHODS}

\section{BACTERIAL STRAINS}

Two strains of Escherichia coli (A and B) and a single Staphylococcus aureus were isolated from blood culture specimens by the Children's Hospital of Philadelphia Microbiology Laboratory. A third strain of $E$. coli $(\mathrm{C})$ was provided by the Babies Hospital Microbiology Laboratory, Columbia Presbyterian Medical Center, New York. Organisms were maintained on nutrient agar slants and inoculated weekly on MacConkey plates $(E$. coli) or sheep blood agar ( $S$. aureus). The minimum inhibitory concentrations to gentamicin for $E$. coli A and B were $\leq 1 \mu \mathrm{g} / \mathrm{ml}$ and for $S$. aureus, $\leq 2 \mu \mathrm{g} / \mathrm{ml}$. The minimum bactericidal concentration for $E$. coli $\mathrm{C}$ was $5 \mu \mathrm{g} / \mathrm{ml}$. A minimum inhibitory concentration was not determined for this organism.

\section{MEDIA AND ANTIBIOTIC PREPARATION}

Nutrient agar, containing beef extract and peptone (Difco Laboratories) was used for all experiments. Media were prepared following manufacturer's instructions, and the gentamicin was added to the media just before pouring the plates.

Gentamicin (Clinical Laboratory Standard; Schering Corporation, Kenilworth, NJ; specific activity, $568 \mu \mathrm{g} / \mathrm{mg}$ ) was weighed in powder form, dissolved in phosphate-buffered saline ( $\mathrm{pH} 7.2)$, and sterilized by passage through a $0.2 \mu \mathrm{m}$ filter (Gelman, Ann Arbor, MI). A $100 \mathrm{ml}$ volume $(1 \mathrm{mg} / \mathrm{ml})$ was divided in $5 \mathrm{ml}$ aliquots and maintained at $-70^{\circ} \mathrm{C}$. The gentamicin plates were kept refrigerated until use within 10 days.

\section{ILLUMINATION}

A phototherapy unit with eight blue lights (Westinghouse Special Blues) was used to provide illumination ( $88 \%$ of output between 425 and $475 \mathrm{~nm}$ ). The unit was protected from direct sunlight and air cooled to maintain the culture plates at $27 \pm 1^{\circ} \mathrm{C}$. The distance between the agar surface and the light source was adjusted to maintain a fluence rate $(450 \mathrm{~nm})$ of $141 \mu \mathrm{W} / \mathrm{cm}^{2}$. Photometric measurements were made with an IL $600 \mathrm{~A}$ photometer coupled to an IL 60 photodensitometer manufactured by International Light, Inc.

\section{INOCULATION OF PLATES}

Overnight cultures in trypticase soy broth $\left(2\right.$ to $\left.3 \times 10^{9} \mathrm{cfu} / \mathrm{ml}\right)$ were diluted tenfold, and $0.1 \mathrm{ml}$ was inoculated on plates containing gentamicin. Plates were either photoirradiated or immediately incubated in the dark. Colony counts were determined at 48 and $72 \mathrm{hr}$ and expressed as mutants per $10^{6}$ organisms plated. To 
quantitate the number of organisms in the original inoculum, the overnight culture was diluted by a factor of $10^{6}$, and $0.1 \mathrm{ml}$ was inoculated on plates without gentamicin.

\section{PHOTOIRRADIATION OF BACTERIA}

To determine the effect of light on the production of gentamicinresistant mutants, $E$. coli strains $\mathrm{A}, \mathrm{B}$, and $\mathrm{C}$ and $S$. aureus were inoculated on nutrient agar containing specified concentrations of gentamicin. One-half the plates were immediately incubated in the dark, and the remainder were photoirradiated for $6 \mathrm{hr}$ and then incubated.

\section{RECOVERY OF GENTAMICIN-RESISTANT MUTANTS WITH INCREASING DURATION OF PHOTOTHERAPY}

To determine the effect of increasing duration of phototherapy, E. coli A was inoculated on plates containing gentamicin $(6 \mu \mathrm{g} /$ $\mathrm{ml}$ ) and photoirradiated for periods ranging from 1 to $6 \mathrm{hr}$. Control plates, containing an equal number of organisms and an identical concentration of gentamicin, were incubated in the dark.

RECOVERY OF GENTAMICIN-RESISTANT MUTANTS FROM PLATES INOCULATED WITH INCREASING NUMBERS OF BACTERIA

To determine the effect of increasing inoculum size on the recovery of gentamicin-resistant organisms, $10^{6}, 10^{7}$, or $10^{8} \mathrm{E}$. coli A were inoculated on plates containing gentamicin $(6 \mu \mathrm{g} / \mathrm{ml})$ and photoirradiated for $6 \mathrm{hr}$. Control plates, inoculated in the same fashion, were incubated in the dark.

\section{VIABILITY OF BACTERIA AFTER PHOTOIRRADIATION}

To determine the viability of $E$. coli $\mathrm{A}$ and $S$. aureus after photoirradiation, $10^{2}$ organisms were plated on nutrient agar without gentamicin and exposed to phototherapy for $6 \mathrm{hr}$. Control plates were kept in the dark.

\section{STABILITY OF MUTANTS}

To evaluate the stability of the gentamicin-resistant $E$. coli A mutants, single colonies were removed from plates containing gentamicin $(6 \mu \mathrm{g} / \mathrm{ml})$ and subcultured on gentamicin-free blood agar plates. After $24 \mathrm{hr}$ of incubation, single colonies were isolated and reinoculated on agar plates containing gentamicin $(6 \mu \mathrm{g} / \mathrm{ml})$.

\section{CONTROL DATA}

Control experiments were performed to determine if phototherapy had any measureable adverse effects on the media and/or gentamicin.

\section{IRRADIATION OF MEDIA WITHOUT GENTAMICIN}

Plates without gentamicin were exposed to $6 \mathrm{hr}$ of phototherapy before inoculation with $E$. coli A and $S$. aureus. After photoirradiation, $10^{2}$ organisms were inoculated on each plate and incubated in the dark. Identical plates, which had not been photoirradiated, were inoculated with $10^{2}$ bacteria and incubated.

\section{IRRADIATION OF MEDIA WITH GENTAMICIN}

Plates containing gentamicin $(6 \mu \mathrm{g} / \mathrm{ml})$ were illuminated for 6 hr before inoculation with $E$. coli A. After photoirradiation, $10^{7}$ organisms were inoculated on the irradiated plates and immediately incubated in the dark. Identical plates, which had not been photoirradiated, were inoculated with $10^{7}$ organisms and incubated.

\section{IRRADIATION OF GENTAMICIN WITHOUT MEDIA}

Gentamicin was photoirradiated for $6 \mathrm{hr}$, and plates containing photoirradiated antibiotic $(6 \mu \mathrm{g} / \mathrm{ml})$ were prepared. E. coli $\left(10^{7}\right)$ were inoculated on these plates and on control plates, containing gentamicin $(6 \mu \mathrm{g} / \mathrm{ml})$ which had not been photoirradiated. All plates were immediately incubated in the dark.

\section{STATISTICS}

Data were analyzed using the Student's independent $t$ test.

\section{RESULTS}

\section{PHOTOIRRADIATION OF BACTERIA}

Table 1 illustrates the number of gentamicin-resistant mutants recovered with increasing gentamicin concentrations in both light and dark environments. At every antibiotic concentration tested, there were increased numbers of gentamicin-resistant mutants on photoirradiated plates compared to those kept in the dark. This effect was observed for each of the four organisms studied. The ratio of the number of mutants on photoirradiated plates to the number of mutants on nonirradiated plates varied from 1.5 to 108.9. In general, the mutagenic effect of light was most evident at the lower gentamicin concentrations.

Table 1. Photoirradiation of bacteria

\begin{tabular}{|c|c|c|c|}
\hline \multirow{2}{*}{$\begin{array}{l}\text { Gentamicin } \\
\text { concentration }\end{array}$} & \multicolumn{2}{|c|}{ Mutant no. $/ 10^{6}$ bacteria $^{1}$} & \multirow{2}{*}{$\begin{array}{l}\text { Photoirradiated/ } \\
\text { nonirradiated } \\
\text { ratio }\end{array}$} \\
\hline & rradiated & Photoirradiated & \\
\hline
\end{tabular}

Escherichia coli $\mathrm{A}$

$\begin{array}{rrcl}1.0 & 94.1 & 152.4 & 1.6 \\ 2.0 & 19.0 & 76.1^{2} & 4.0 \\ 4.0 & 6.8 & 16.1 & 2.4 \\ 6.0 & 4.4 & 10.6^{3} & 2.4 \\ 7.0 & 4.7 & 8.3 & 1.8 \\ 8.5 & 5.0 & 10.4^{2} & 2.1 \\ 9.0 & 5.8 & 10.4^{2} & 1.8 \\ 9.5 & 6.0 & 10.9 & 1.8 \\ 10.0 & 5.1 & 9.0^{3} & 1.8\end{array}$

Escherichia coli $\mathrm{B}$

$\begin{array}{rrrr}1.0 & 45.5 & 151.5^{4} & 3.3 \\ 2.0 & 30.3 & 121.2^{4} & 4.0 \\ 4.0 & 8.3 & 28.9^{4} & 3.5 \\ 6.5 & 2.9 & 8.9^{5} & 3.1 \\ 7.0 & 1.2 & 5.4^{4} & 4.7 \\ 8.0 & 1.4 & 5.4 & 3.9 \\ 9.0 & 0.7 & 2.9^{6} & 4.1 \\ 10.0 & 1.0 & 2.4^{4} & 2.5\end{array}$

Escherichia coli $\mathrm{C}$
6.0
$2.1 \times 10^{-2}$
$2.3^{4}$
108.9

Staphylococcus aureus

$\begin{array}{lrrr}0.50 & 22.7 & 194.9^{2} & 8.6 \\ 0.75 & 7.6 & 34.1^{2} & 4.5 \\ 1.00 & 5.0 & 9.9^{2} & 1.8 \\ 1.25 & 2.7 & 5.0 & 1.9 \\ 1.50 & 1.9 & 4.5 & 2.4\end{array}$

\footnotetext{
'Significant difference between photoirradiated and nonirradiated plates

${ }^{2} P<0.05$

${ }^{3} P<0.02$

${ }^{4} P<0.001$.

${ }^{5} \mathrm{P}<0.005$.

${ }^{\circ} P<0.01$
} 
RECOVERY OF GENTAMICIN-RESISTANT MUTANTS WITH INCREASING DURATION OF PHOTOTHERAPY

The number of gentamicin resistant mutants produced by 1 to $6 \mathrm{hr}$ of photoirradiation are shown in Figure 1. There was a linear relationship between the duration of phototherapy and the number of gentamicin-resistant $E$. coli A produced (r $=0.95 ; P<$ 0.001 ). A single hour of photoirradiation was sufficient to demonstrate a significant increase in the number of mutants compared to dark controls.

\section{RECOVERY OF GENTAMICIN-RESISTANT MUTANTS ON PLATES INOCULATED WITH INCREASING NUMBERS OF BACTERIA}

At a gentamicin concentration of $6 \mu \mathrm{g} / \mathrm{ml}$, the number of mutants recovered per $10^{6}$ organisms inoculated on photoirradiated and nonirradiated plates decreased as the number of bacteria were increased from $10^{6}$ to $10^{7}$ per plate $(P=\mathrm{NS})$. However, there was a significant decrease in mutant recovery when the number of $E$. coli A was increased from $10^{7}$ to $10^{8}$ organisms per plate ("photoirradiated" $P<0.01$; "nonirradiated" $P<0.001$ ). At all concentrations of organisms, the number of mutants on photoirradiated plates was significantly greater than on nonirradiated plates (Table 2).

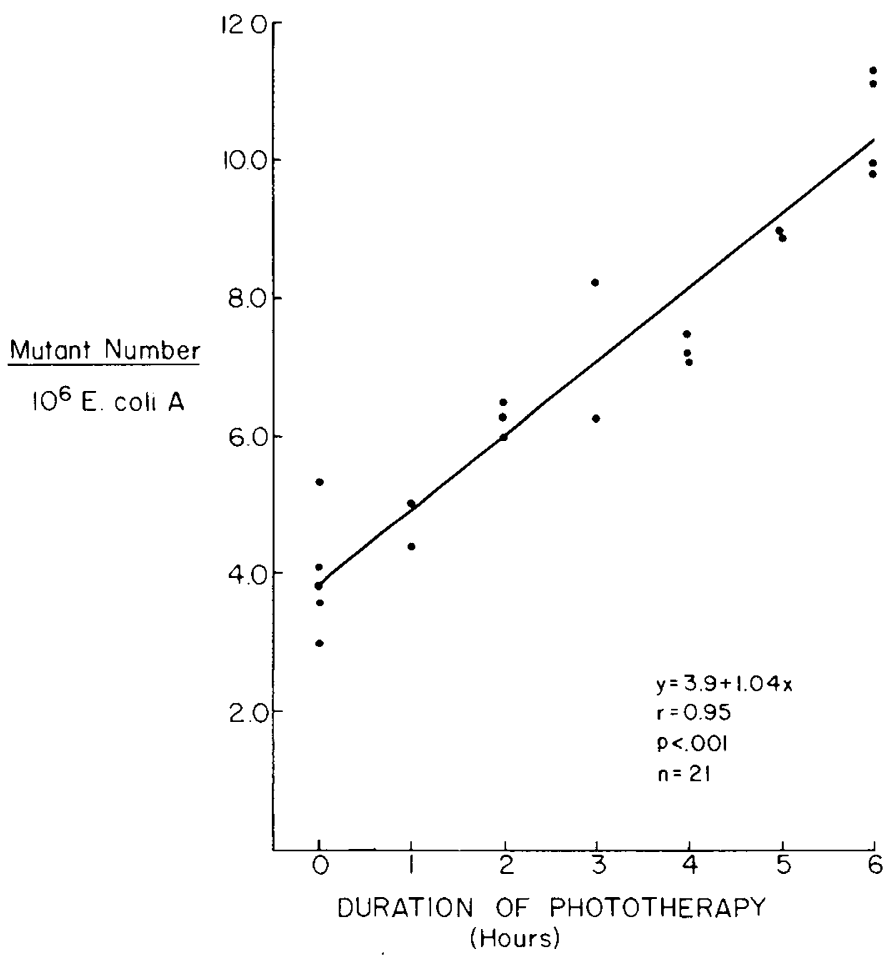

Fig. 1. Recovery of gentamicin-resistant mutants with increasing duration of phototherapy.

Table 2. Recovery of gentamicin-resistant E. coli $\mathrm{A}$ on plates inoculated with increasing numbers of bacteria ${ }^{1}$

\begin{tabular}{ccc}
\hline & \multicolumn{2}{c}{ Mutant no. $/ 10^{6}$ bacteria } \\
\cline { 2 - 3 } Organism & Dark & Light \\
\hline $10^{6}$ & 7.6 & $13.6^{2}$ \\
$10^{7}$ & 5.2 & $11.4^{3}$ \\
$10^{8}$ & 2.3 & $3.9^{4}$ \\
\hline
\end{tabular}

\footnotetext{
'Significant difference between photoirradiated and nonirradiated plates.

${ }^{2} P<0.05$.

${ }^{3} P<0.0001$

${ }^{4} P<0.001$.
}

VIABILITY OF BACTERIA AFTER PHOTOIRRADIATION

The mean number of $E$. coli $\mathrm{A}$ on photoirradiated plates lacking gentamicin $(66.8 \pm 4.0 ; \mathrm{m} \pm$ S.E.) did not differ from the mean number of organisms on plates kept in the dark $(65.0 \pm 2.0)$. In contrast, there was a significant decrease in the viability of $S$. aureus exposed to light (photoirradiated, $62.8 \pm 10.2$; nonirradiated, $88.8 \pm 3.6 ; P<0.05)$.

\section{STABILITY OF MUTANTS}

E. coli A mutants resistant to gentamicin $(6 \mu \mathrm{g} / \mathrm{ml})$ remained resistant after subculture on gentamicin-free blood agar plates.

\section{CONTROL DATA}

Irradiation of Media Without Gentamicin. Photoirradiation of media did not alter its ability to support the growth of $E$. coli A or $S$. aureus. The mean colony counts for both organisms on photoirradiated and nonirradiated plates were not significantly different $(E$. coli A "irradiated media," $75.6 \pm 5.4, \mathrm{~m} \pm$ S.E.; "nonirradiated media," $76.3 \pm 5.2 ; S$. aureus irradiated media, $78.7 \pm$ 8.4; nonirradiated media, $83.0 \pm 1.9$ ).

Irradiation of Media With Gentamicin. The mean number of gentamicin-resistant $E$. coli A recovered on plates in which gentamicin and media were both irradiated before inoculation did not differ from the mean number of mutants on identical plates not photoirradiated. (Mutant number $/ 10^{6}$ bacteria: "nonirradiated media and gentamicin," 4.4; "irradiated media and gentamicin," 4.6).

Irradiation of Gentamicin Without Media. Irradiation of gentamicin before plate preparation did not affect the number of mutants obtained. (Mutant number $/ 10^{6}$ bacteria: irradiated gentamicin, 7.6; nonirradiated gentamicin, 7.9).

\section{DISCUSSION}

This study demonstrates that a brief exposure to phototherapy induces mutations to gentamicin resistance in previously sensitive strains of $E$. coli and $S$. aureus. The mutagenic effect was observed over a wide range of gentamicin concentrations and correlated in a linear fashion with increasing duration of photoirradiation.

Three mechanisms may be responsible for the appearance of gentamicin-resistant mutants. In bacteria recovered from clinical specimens, resistance is usually mediated by extrachromosomal DNA, i.e., plasmids containing resistance determinants $(2,4-6)$. Bacteria carrying these extrachromosomal elements inactivate antibiotics by means of enzymatic reactions. Gentamicin resistance obtained in vitro is frequently due to failure of the antibiotic to reach the ribosomal target or to structural alteration of the ribosomal binding site for gentamicin $(1,9)$. Mutations induced by the light used in phototherapy most probably involve one of the in vitro mechanisms.

For each of the bacterial strains tested, the mutagenic effect of phototherapy was most evident at the lower gentamicin concentrations. The mechanism(s) responsible for the increased recovery of mutants resistant to low levels of gentamicin after photoirradiation is unknown. One possibility is that different mechanisms were responsible for bacterial resistance at low and high gentamicin concentrations. Two classes of nalidixic acid resistant E. coli $\mathrm{K}-12$ have previously been demonstrated by Hane and Wood (7). Phototherapy may be more efficient in initiating the mechanisms responsible for low-level gentamicin resistance. An alternative explanation may be that at higher gentamicin concentrations the organisms were rapidly killed before mutations induced by phototherapy could be expressed. Discovery of the actual explanation will require further investigations.

An unexpected finding in this study was that the mutant recovery per $10^{6}$ organisms inoculated decreased as the number of bacteria were increased exponentially. This decrease in the recovery of gentamicin-resistant mutants among both photoirradiated and nonirradiated bacteria may have been due to competition for 
nutrients in the agar medium, decreasing organism survival. The viability of $E$. coli A was not significantly affected by photoirradiation. However, a significant number of $S$. aureus were killed by the light used in phototherapy. It is somewhat surprising that although blue light was mutagenic for $E$. coli, we could not demonstrate a bactericidal effect. The control experiments demonstrated that the media was nutritionally adequate and did not contain toxic or mutagenic substances after photoirradiation. In addition, the bactericidal effect of gentamicin was not altered by illumination.

There was a linear increase in the number of resistant $E$. coli A as the duration of photoirradiation was increased from 1 to $6 \mathrm{hr}$. An hour of photoirradiation was sufficient to produce gentamicinresistant mutants. The minimum duration of photoirradiation necessary to produce resistant $E$. coli A was not determined. It is unknown whether this linear dose response relationship is unique for $E$. coli or represents a more general phenomenon.

The increased number of gentamicin-resistant organisms after photoirradiation is not surprising in view of the known ability of near UV and visible light to modify DNA both in mammalian cells and bacteria (10-13). As early as 1943, light in the near UV spectrum had been shown to be lethal for several species of microorganisms (8). Webb (15) demonstrated a biomodal mutagenic effect of light with maximal effect at 265 and $470 \mathrm{~nm}$. In their laboratory, streptomycin resistant $E$. coli were produced by these wave lengths. Cabrera-Juarez and Espinosa-Lara in 1974 (3) induced streptomycin-resistant Hemophilus influenzae by exposing them to black light between 325 and $400 \mathrm{~nm}$ (3). Using strains of Salmonella typhimurium auxotrophic for histidine, Speck and Rosenkranz (12) demonstrated that phototherapy most probably alters bacterial DNA by inducing base substitution mutations.

The production of gentamicin-resistant mutants after a relatively brief exposure to the light used in phototherapy may be of clinical importance. Storer et al. in 1975 (14) completed a similar study also investigating the effect of phototherapy on three bacterial strains. They photoirradiated Staphylococcus aureus, Escherichia coli, and Streptococcus pyogenes for intervals up to $48 \mathrm{hr}$. Streptococcus pyogenes demonstrated cell wall defects after illumination as noted by a change in colony appearance and a decrease in growth rate. $S$. aureus exhibited increased sensitivity to kanamycin. E. coli was not affected. The disparity between Storer's results and our may be explained by the higher fluence used in our study, the specific strains tested, or the methodology used in the detection of mutants. The production of gentamicin resistant mutants with photoirradiation may not represent a general phenomena. The relationship between the development of bacterial resistance to other antimicrobial agents and use of phototherapy will require further investigation.

\section{REFERENCES AND NOTES}

1. Appel, G. B., and Neu, H. C.: Gentamicin in 1978. Ann. Intern. Med., 89: 528 (1978).

2. Benveniste, R., and Davies, J.: Mechanisms of antibiotic resistance in bacteria. Ann. Rev. Biochem., 42: 471 (1973).

3. Cabrera-Juarez, E., and Espinosa-Lara, M.: Lethal and mutagenic action of black light (325 to $400 \mathrm{~nm}$ ) on Haemophilius influenzae in the presence of air. J. Bacteriol., 117: 960 (1974).

4. Davies, J., Brezinska, M., and Benveniste, R.: R factors: biochemical mechanisms of resistance to aminoglycoside antibiotics. Ann. N. Y. Acad. Sci., 182: 226 (1971).

5. Davies, J., and Kass, E. H.: Session 1: chemistry and microbiology. Bacterial resistance to aminoglycosides antibiotics. J. Infect. Dis., I24: 57 (1971).

6. Dowding, J. E.: Mechanisms of gentamicin resistance in Staphylococcus aureus. Antimicrob. Agents Chemother., 11: 47 (1977).

7. Hane, M. W., and Wood, T. H.: Escherichia coli K-12 mutants resistant to nalidixic acid: genetic mapping and dominance studies. J. Bacteriol., 99: 239 (1969).

8. Hollaender, A.: Effect of long ultraviolet light and short visible irradiation (3500 $4400 \AA$ ) on E. coli. J. Bacteriol., 46: 531 (1943).

9. Kuhberger, R., Piepersberg, W., Potaet, A., Buckel, P., and Böck, A.: Alteration of ribosomal protein $\mathrm{L} 6$ in gentamicin-resistant strains of Escherichia coli. Effects of fidelity of protein synthesis. Biochemistry, 18: 187 (1979).

10. Speck, W. $\Upsilon$., Chang, C. C., and Rosenkranz, H. S.: In vitro studies of effects of light and riboflavin on DNA and HeLa cells. Pediatr. Res., 9: 150 (1975).

11. Speck, W. T., and Rosenkranz, H. S.: The bilirubin-induced photodegradation of DNA. Pediatr. Res., 9: 703 (1975).

12. Speck, W. T., and Rosenkranz, H. S.: Base substitution mutations induced in Salmonella strains by visible light $(450 \mathrm{~nm})$. Photochem. Photobiol., 21: 369 (1975).

13. Speck, W. T., and Rosenkranz, H. S.: Intracellular deoxyribonucleic acid-modifying activity of phototherapy lights. Pediatr. Res., 10: 553 (1976).

14. Storer, J. S., Gutman, L. T., and Brumley, G. W.: Bacteria and phototherapy. Pediatr. Res., 8: 429 (1974).

15. Webb, R. B.: Photodynamic lethality and mutagenesis in the absence of added sensitizers. Research Progress in Organic, Biological and Medicinal Chemistry, 3: 511 (1972).

16. The authors thank Barbara Erwins for editorial assistance.

17. Requests for reprints should be addressed to: Richard A. Polin, M.D., The Children's Hospital of Philadelphia, 34th Street \& Civic Center Boulevard, Philadelphia, PA 19104 (USA)

18. Received for publication October 23, 1978.

19. Accepted for publication October 3, 1980. 